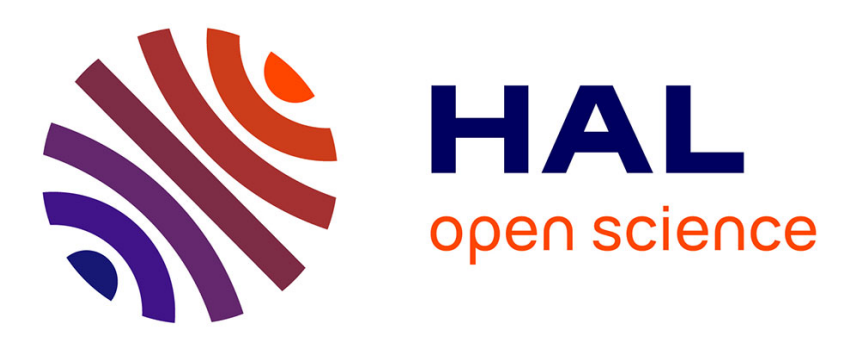

\title{
Experimental study of temperature heterogeneity in metallic materials under high strain rate solicitation
}

Nicolas Ranc, Vincent Pina, Pasqua Herve, Laurent Taravella, Pierre-François

Louvigne

\section{- To cite this version:}

Nicolas Ranc, Vincent Pina, Pasqua Herve, Laurent Taravella, Pierre-François Louvigne. Experimental study of temperature heterogeneity in metallic materials under high strain rate solicitation. Journal de Physique IV Proceedings, 2003, 110, pp.417-422. 10.1051/jp4:20020729 . hal-00283481

\section{HAL Id: hal-00283481 \\ https://hal.science/hal-00283481}

Submitted on 18 Mar 2018

HAL is a multi-disciplinary open access archive for the deposit and dissemination of scientific research documents, whether they are published or not. The documents may come from teaching and research institutions in France or abroad, or from public or private research centers.
L'archive ouverte pluridisciplinaire HAL, est destinée au dépôt et à la diffusion de documents scientifiques de niveau recherche, publiés ou non, émanant des établissements d'enseignement et de recherche français ou étrangers, des laboratoires publics ou privés. 


\title{
Experimental study of temperature heterogeneity in metallic materials under high strain rate sollicitation
}

\author{
N. Ranc, V. Pina, P. Hervé, L. Taravella ${ }^{1}$ and P.F. Louvigné ${ }^{1}$ \\ Laboratoire d'Énergétique et d'Économie d'Énergie, Université Paris $X, 1$ chemin Desvallières, \\ 92410 Ville-d'Avray, France \\ ${ }^{1}$ Centre Technique d'Arcueil DGADCE, 16 bis avenue Prieur de la Côte d'Or, \\ 94114 Arcueil cedex, France
}

\begin{abstract}
Our study deals with the dynamic behaviour of metallic materials and in particular of titanium alloy TA6V. For high strain rates, we can notice the occurrence of a phenomenon called adiabatic shearing. It is about a plastic instability, which results in the appearance of a localisation of the deformation in the narrow bands. The width of these bands is around ten micrometers of broad. The mechanisms concerned in the formation of these bands are partly known, but their modelling remains a complex problem. This article deals with an experimental study of this phenomenon on torsion Hopkinson bars. The surface temperature of the specimen is measured by optical pyrometry with a bar of $32 \mathrm{InSb}$ detectors. This experimental device allows to obtain the time evolution of the temperature along the torsion axis of the specimen. The space resolution is about $50 \mu \mathrm{m}$ and the measured temperatures vary between $50^{\circ} \mathrm{C}$ and $300^{\circ} \mathrm{C}$. This measurement makes it possible to study the onset of the localisation precisely.
\end{abstract}

\section{INTRODUCTION}

This study deals with the dynamic behaviour of metallic materials and in particular of titanium alloy TA6V. For high strain rates, we can notice the occurrence of a phenomenon called adiabatic shearing [1]. It is about a plastic instability, which results in the onset of a localisation of deformation in narrow bands. The width of these bands is around ten micrometers of broad.

In metals large proportion of plastic deformation energy is converted into heat in the material. In dynamic solicitation, the heat transfers by conduction are negligible. The consequence of these effects is the local growth of the material temperature and the thermal softening of the material. This catastrophic process is characteristic of plastic instability.

The mechanisms concerned in the formation of these bands are also partly known, but their modelling remains a complex problem.

Numerous studies were interested in the temperature measurement in the adiabatic shear bands [2-6]. The authors tried to determine the temperature maximum reached in the shear bands. But the various techniques used are not enough sensitive to make it possible to visualise the beginning of the band formation.

In this paper we focus ourselves on the onset of the strain localisation and we propose an experimental method to measure the evolution of the temperature heterogeneity with a time resolution of $1 \mu \mathrm{s}$ and in a temperature range of $50^{\circ} \mathrm{C}$ to $300^{\circ} \mathrm{C}$.

\section{EXPERIMENTAL DEVICE}

\subsection{Mechanical part}

\subsubsection{Solicitation device}

To reproduce adiabatic shear bands we use the torsional Hopkinson bars. This technique allows to load dynamically the specimen at a shear strain rate of around $10^{3} \mathrm{~s}^{-1}$. 
The specimen is fixed at the ends of two aluminium alloy bars $3 \mathrm{~cm}$ in diameter and $3 \mathrm{~m}$ in length $3 \mathrm{~cm}$ (incident bar and transmitter bar). Before the test, a brake blocks the incident bar at the point $\mathrm{F}$ and an hydraulic engine in $M$ allows to impose a torsion angle of to the incident bar (figure 1). After the relaxation of the brake, a torsional loading pulse of constant amplitude propagates down the bar towards the specimen. Part of the wave is reflected and the other is transmitted to the transmitter bar.

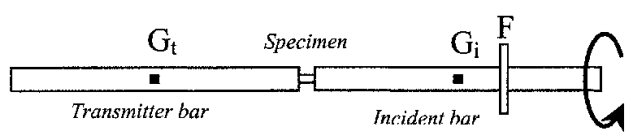

Figure 1 : Torsional Hopkinson bar device

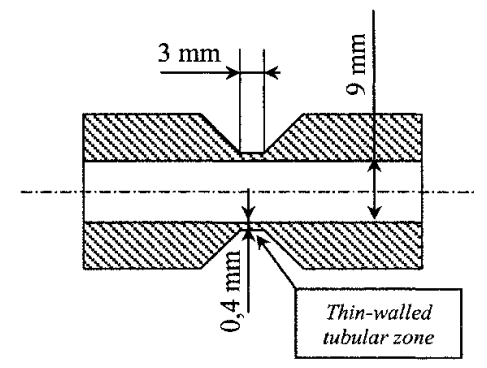

Figure 2 : Spatial heterogeneity of temperature

\subsubsection{Specimen geometry}

The useful part of specimen has a thin-walled tubular geometry (the specimen gage)(figure 2). There is a small reduction of section in the center of the interest zone in order to be certain that the shear band appear on this place. The specimen has a gage length of $3 \mathrm{~mm}$, and an internal diameter of $9 \mathrm{~mm}$. The wall thickness is of $0,4 \mathrm{~mm}$ and the roughness of the different surface is around $\mathrm{Ra}=0,3 \mu \mathrm{m}$. The table 3 gives the composition of the titanium alloy TA6V.

\begin{tabular}{|c|c|c|c|c|c|}
\hline Weight \% & $\mathrm{Al}$ & $\mathrm{V}$ & $\mathrm{Fe}$ & $\mathrm{C}$ & $\mathrm{O}$ \\
\hline TA6V & $5,72 \%$ & $4,04 \%$ & $0,147 \%$ & $0,034 \%$ & $0,08 \%$ \\
\hline
\end{tabular}

Table 3 : Chimical composition of the titanium alloy TA6V

\subsubsection{Stress and strain measurements}

The gauges placed in medium of the incident bar $\left(G_{i}\right)$ and the transmitter bar $\left(G_{t}\right)$ enable to determine the shear strain of the bars. We can distinguish an incident $\varepsilon_{i}(t)$, a reflected $\varepsilon_{r}(t)$ and transmitter strain $\varepsilon_{i}(t)$ (figure 4). From these data, we calculate the torsion angle of torsion of the end of the incident and transmitter bars $\left(\theta_{i}\right.$ and $\left.\theta_{t}\right)$ and the torque applied to the specimen $\left(M_{i}\right.$ and $\left.M_{t}\right)$ :

$$
\begin{aligned}
& \theta_{i}=\frac{2 c}{R_{b}}\left(-\varepsilon_{i}\left(t-\frac{l_{i}}{c}\right)+\varepsilon_{n}\left(t+\frac{l_{i}}{c}\right)\right) \quad \text { and } \quad \theta_{t}=\frac{2 c}{R_{b}} \cdot \varepsilon_{t}\left(t+\frac{l_{t}}{c}\right) \\
& M_{i}=\frac{2 \mu J}{R_{b}}\left(\varepsilon_{i}\left(t-\frac{l_{i}}{c}\right)+\varepsilon_{r}\left(t+\frac{l_{i}}{c}\right)\right) \text { and } M_{t}=\frac{2 \mu J}{R_{b}} \cdot \varepsilon_{t}\left(t+\frac{l_{t}}{c}\right)
\end{aligned}
$$

with $c$ the celerity of the torsion waves, $l_{i}$ and $l_{t}$ the distance between the gauge and the end of respectively the incident and transmitter bars, $\mu$ the shear modulus, $J$ the torsion quadratic moment of the bar and $R_{b}$ the ray of the bar.

From relation (1) and (2) we can calculate the nominal strain of the specimen: 


$$
\gamma=\frac{\theta_{s}-\theta_{e}}{l} R_{e}
$$

To determine the shear stress, we can suppose the balance of the torques applied to the test-tube. This assumption is generally valid except at the beginning of test:

$$
\tau=\frac{M}{R_{e} \cdot S_{e}} \quad \text { with } \quad M=M_{i}=M_{t}
$$

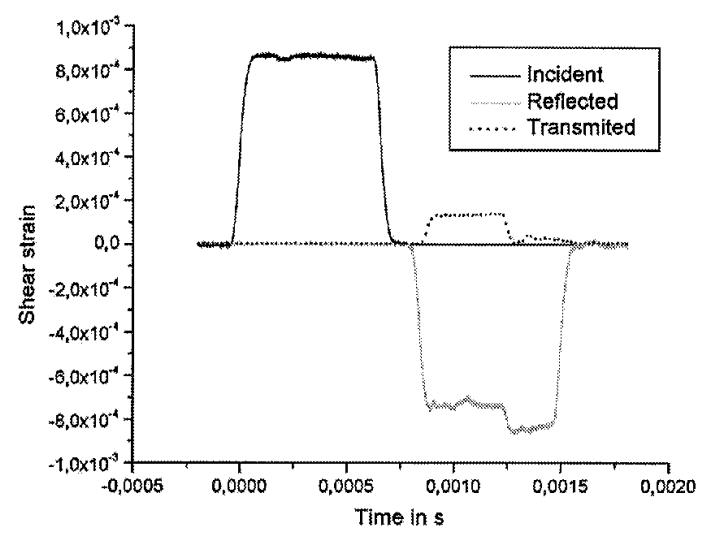

Figure 4 : Incident $\varepsilon_{i}(t)$, reflected $\varepsilon_{r}(t)$ and transmitter $\varepsilon_{t}(t)$ strain of the bars

\subsection{Pyrometric measurements}

\subsubsection{Optical device}

To determine the temperature evolution on the specimen without disturbing shear band formation, we use pyrometry technique. This optical technique is based on the study of the specimen radiation in the tubular zone.

In order to measure the specimen surface temperature we use a bar of 32 photovoltaic indiumantimonide ( $\mathrm{InSb}$ ) detectors. The spectral range of this type of detector is mainely in infrared domain between $0,5 \mu \mathrm{m}$ and $5,5 \mu \mathrm{m}$ wavelength. Each detector output is individualy recorded on a Nicolet Multipro data acquisition. The response time of this device is around 500 nanoseconds enabling us to study very fast temperature variations. The 32 detectors are coupled with a calcium fluoride lens with a focal length of $150 \mathrm{~mm}$. This optical device allows to measure the time evolution of the temperature simultaneously on 32 areas of $65 \mu \mathrm{m}$ per $65 \mu \mathrm{m}$ across a line on the specimen gage (figure 6). The space between two areas is $27 \mu \mathrm{m}$.

Our device is optimized to measure low temperature about $50^{\circ} \mathrm{C}$. The optical system is designed to collect the maximum of specimen radiation (high transmission coefficient of calcium fluoride and maximum solid angle). To reduce the thermal noise, we choose a magnification of the optical system near to 1 . The only disadvantage of this optical device is the chromatic aberrations due to lens refraction.

\subsubsection{Calibration on blackbody reference}

The calibration the optical device is performed using a reference source like a blackbody. The output of each detector is measured versus the temperature. The figure 5 represents the calibration curve of the first detector. 


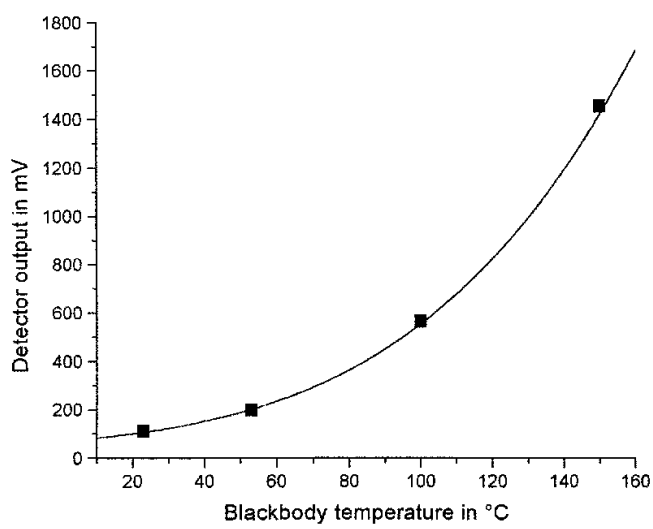

Figure 5 : Calibration curve of detector vs blackbody temperature

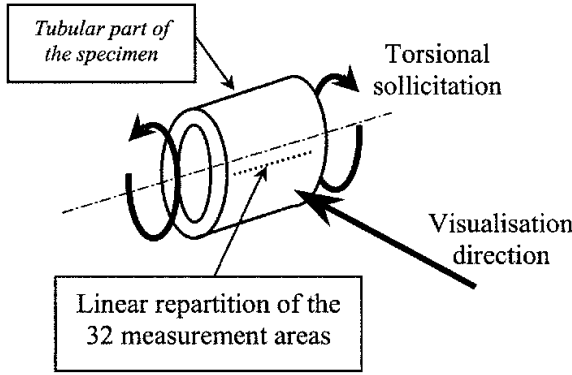

Figure 6 : Visualisation of the temperature measurement areas on the specimen

\subsubsection{Emissivity correction}

The real surface radiation is bound with blackbody radiation by his emissivity value. The variations of the emissivity surface depend on its temperature, its roughness and possible phase transition of material. The figure 7 shows the emissivity variation versus temperature. In the following paper we will consider that the emissivity variations are negligible. The emissivity is taken equal to 0.26 . If we take into account of this emissivity value we obtain a new calibration curve for the specimen surface (figure 8).

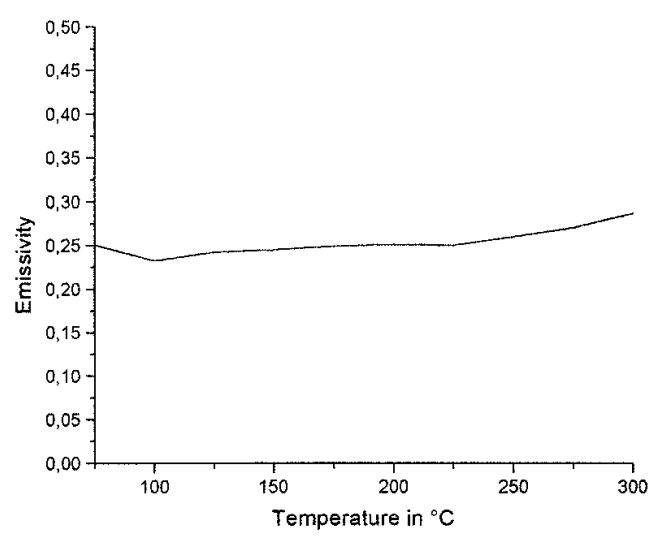

Figure 7 : Emisivity variation versus temperature

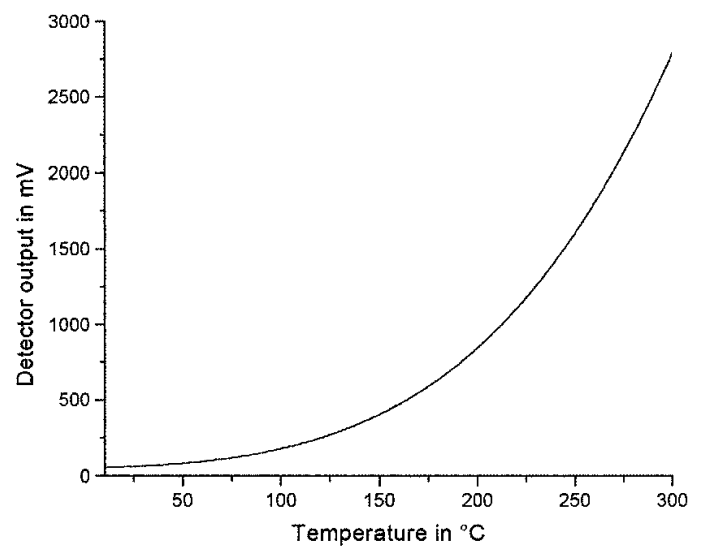

Figure 8 : Calibration curve of detector vs real temperature of the specimen

\section{RESULTS}

\subsection{Stress and temperature evolutions}

Figure 9 representes simultaneously the measurement of the shear stress and the temperature on the detector where the temperature is the highest versus the nominal shear strain. The strain rate during this test remains constant and equal to $930 \mathrm{~s}^{-1}$. Figure 10 shows the space distribution of the temperature versus time. 
We can distinguish two stages: during the first the temperature remains homogeneous and increases in a linear way $\left(0.5^{\circ} \mathrm{C} / \mu \mathrm{s}\right)$. The temperature difference between the edge and the center of the specimen comes from the section reduction (paragraph 2.2.1.). During the second stage the temperature becomes heterogeneous. The stress collapse corresponding to the onset of the strain localization is accompanied by an abrupt increase of the temperature $\left(6^{\circ} \mathrm{C} / \mu \mathrm{s}\right)$. A fast increase in the temperature is also observed on the edges of the specimen but this heating is not related to the adiabatic shearing phenomenon. It can be explained by the chromatic aberrations.

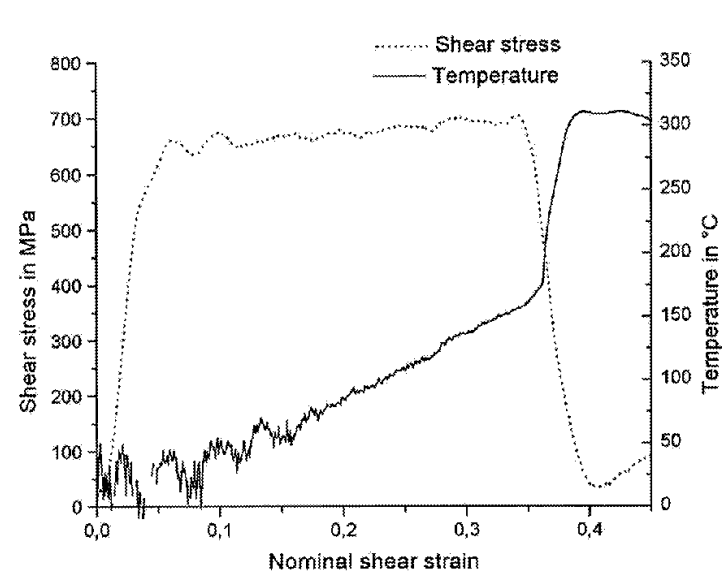

Figure 9 : Stress and temperature versus nominal strain

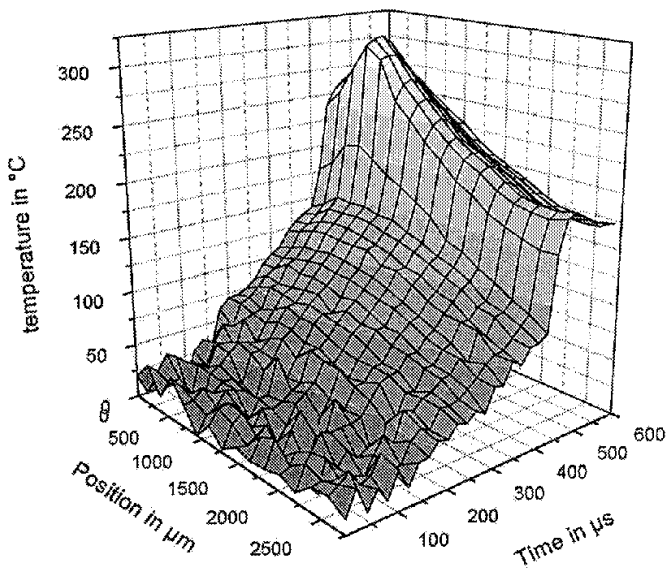

Figure 10 : Spatial heterogeneity of temperature

\subsection{Post mortem visualisation of the shear band}

After test, the specimen is observed under the optical microscope. The figure 11 shows a metallography of the zone observed during the test. It makes obvious an adiabatic shear band of a width of $17 \mu \mathrm{m}$. At the outside of the band, the grains are lengthened and directed according to a particular direction. The angle between this direction and the shear direction is around $45^{\circ}$.

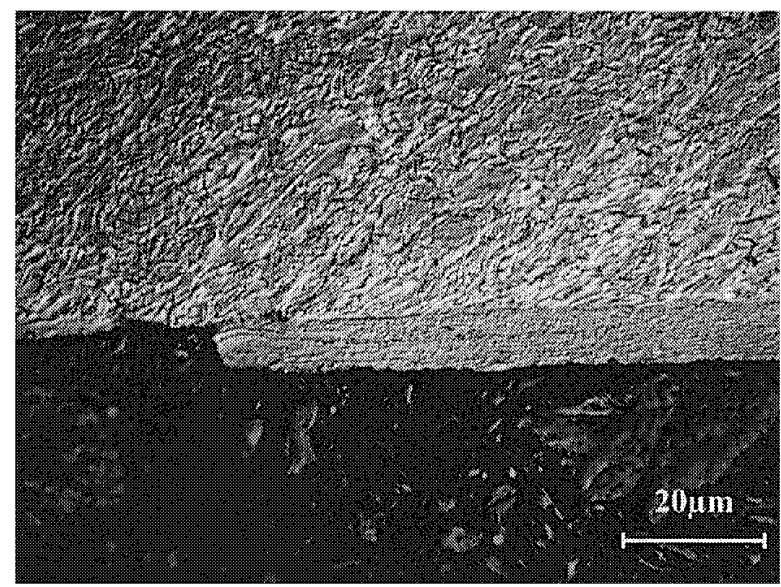

Figure 11 : Post mortem visualisation of the ASB 


\section{CONCLUSION}

The experimental device which was developed in this study makes it possible to measure temperatures varying between $50^{\circ} \mathrm{C}$ and $300^{\circ} \mathrm{C}$ with a time resolution of $1 \mu \mathrm{s}$. It allows to detect the onset of the localisation and to follow the time evolution of an adiabatic shear band.

The disadvantage of this device is that the space resolution is limited by the chromatic aberrations. An improvement of this device would consist in using an achromatic optical system. For example we can replace the lens by mirrors.

\section{Acknowledgements}

We thank MM Sauques, Sigaud and Garrioux from the DGA/DCE/CTA/LOT for providing emissivity results and $\mathrm{M}$. Clisson for the help on dynamic test.

\section{References}

[1] Y. BAI and B. DODD, Adiabatic shear localization Occurrence, Theories and Applications (Pergamon Press, 1992)

[2] A. MARCHAND, J. DUFFY, "An experimental study of the deformation process of adiabatic shear bands in a structural steel" Journal of the Mechanics and Physics of Solids, Vol. 36 No.3 (1988) 251-283 [3] V. PINA, "Mesure de température de bandes de cisaillement adiabatique dans des alliages de titane", Thesis, University of Paris X, France (1997)

[4] N. RANC, V. PINA and P. HERVE "Optical measurementof phase transition and temperature in adiabatic shear bands in titanium alloys" Journal de physique IV France 10 (2000) 347-352

[5] T. ZEHNDER, R. GUDURU, J. ROSAKIS and G. RAVICHANDRAN, "Million frames per second infraredimaging system", Review of Scientific Instruments, Vol. 71 No. 10 (2000)

[6] M. ZHOU, J. ROSAKIS and G. RAVICHANDRAN, "Dynamically propagating shear bands in impact-loaded prenotched plates - I. Experimental investigations of temperature signatures and propagation speed" Journal of the Mechanics and Physics of Solids, Vol. 44 No.6 (1996) 981-1006 